ORIGINAL ARTICLE

\section{Alendronate or Alfacalcidol in Glucocorticoid-Induced Osteoporosis}

\author{
Ron N.J. de Nijs, M.D., Ph.D., Johannes W.G. Jacobs, M.D., Ph.D., \\ Willem F. Lems, M.D., Ph.D., Roland F.J. Laan, M.D., Ph.D., \\ Ale Algra, M.D., Ph.D., Anne-Margriet Huisman, M.D., Ph.D., \\ Erik Buskens, M.D., Ph.D., Chris E.D. de Laet, M.D., Ph.D., \\ Ans C.M. Oostveen, M.D., Ph.D., Piet P.M.M. Geusens, M.D., Ph.D., \\ George A.W. Bruyn, M.D., Ph.D., Ben A.C. Dijkmans, M.D., Ph.D., \\ and Johannes W.J. Bijlsma, M.D., Ph.D., for the STOP Investigators*
}

\section{A B STRACT}

\section{BACKGROUND}

Treatment with glucocorticoids is associated with bone loss starting soon after therapy is initiated and an increased risk of fracture.

\section{METHODS}

We performed a randomized, double-placebo, double-blind clinical trial of 18 months' duration among patients with a rheumatic disease who were starting glucocorticoids at a daily dose that was equivalent to at least $7.5 \mathrm{mg}$ of prednisone. A total of 201 patients were assigned to receive either alendronate $(10 \mathrm{mg})$ and a placebo capsule of alfacalcidol daily or alfacalcidol $(1 \mu \mathrm{g})$ and a placebo tablet of alendronate daily. The primary outcome was the change in bone mineral density of the lumbar spine in 18 months; the secondary outcome was the incidence of morphometric vertebral deformities.

\section{RESULTS}

A total of 100 patients received alendronate, and 101 received alfacalcidol; 163 patients completed the study. The bone mineral density of the lumbar spine increased by 2.1 percent in the alendronate group (95 percent confidence interval, 1.1 to 3.1 percent) and decreased by 1.9 percent in the alfacalcidol group (95 percent confidence interval, -3.1 to -0.7 percent). At 18 months, the mean difference of change in bone mineral density between the two groups was 4.0 percent ( 95 percent confidence interval, 2.4 to 5.5 percent). Three patients in the alendronate group had a new vertebral deformity, as compared with eight patients in the alfacalcidol group (of whom three had symptomatic vertebral fractures) (hazard ratio, 0.4; 95 percent confidence interval, 0.1 to 1.4$)$.

\section{CONCLUSIONS}

During this 18-month trial in patients with rheumatic diseases, alendronate was more effective in the prevention of glucocorticoid-induced bone loss than was alfacalcidol. (ClinicalTrials.gov number, NCT00138983.)
From the Department of Rheumatology and Clinical Immunology (R.N.J.N., J.W.G.J., J.W.J.B.) and the Julius Center for Health Sciences and Primary Care (A.A., E.B.), University Medical Center Utrecht, Utrecht; the Department of Rheumatology, Free University Medical Center, Amsterdam (W.F.L., B.A.C.D.); the Department of Rheumatology, Radboud University Nijmegen Medical Center, Nijmegen (R.F.J.L.); the Department of Rheumatology, Sint Franciscus Hospital, Rotterdam (A.-M.H.); the Department of Rheumatology Twente, Twenteborg Hospital, Almelo (A.C.M.O.); the Department of Rheumatology, University Hospital Maastricht, Maastricht (P.P.M.M.G.); and the Department of Rheumatology, Medical Center Leeuwarden, Leeuwarden (G.A.W.B.) - all in the Netherlands; and the Department of Epidemiology, Scientific Institute of Public Health, Brussels (C.E.D.L.). Address reprint requests to Dr. de Nijs at the Department of Rheumatology and Clinical Immunology, F02 127, University Medical Center Utrecht, P.O. Box 85500, 3508 GA Utrecht, the Netherlands, or at r.denijs@mmc.nl.

*Additional investigators who participated in the Steroid Osteoporosis Prevention (STOP) study are listed in the Appendix.

N EnglJ Med 2006;355:675-84.

Copyright $\odot 2006$ Massachusetts Medical Society. 
$\mathrm{G}$ LUCOCORTICOIDS ARE FREQUENTLY used in patients with rheumatic diseases and are associated with increased bone loss and a risk of fracture..$^{1-3} \mathrm{An}$ important effect of glucocorticoids on bone is the inhibition of bone formation by decreasing the number of osteoblasts and hampering their function. ${ }^{4,5}$ Glucocorticoids also increase the rate of bone resorption by stimulating the formation and action of osteoclasts. Furthermore, glucocorticoids decrease intestinal absorption of calcium and increase renal calcium excretion. ${ }^{5-8}$ Although daily doses of prednisone of $7.5 \mathrm{mg}$ or more have been associated with glucocorticoid-induced osteoporosis, ${ }^{9,10}$ lower doses of the drug have also been linked to such changes. ${ }^{11}$ Active vitamin $\mathrm{D}_{3}$ analogues, such as calcitriol and alfacalcidol, stimulate the formation and action of osteoblasts, ${ }^{12}$ leading to increased bone formation. ${ }^{13}$ These agents prevent bone loss and reduce the risk of vertebral fracture during glucocorticoid therapy. ${ }^{14-16}$

Bisphosphonates induce apoptosis of osteoclasts and inhibit bone resorption. ${ }^{17}$ Alendronate, one of the bisphosphonates, is effective in the prevention and treatment of glucocorticoid-induced osteoporosis. ${ }^{18-20}$ In an open-label study involving patients with a rheumatic disease who were either receiving or starting treatment with glucocorticoids, alendronate was more effective than calcitriol in the preservation of bone. ${ }^{21}$ In renaltransplant recipients, alendronate combined with calcitriol was superior to calcitriol alone in the prevention of bone loss during glucocorticoid therapy. ${ }^{22,23}$ Recent studies showed that alendronate and calcitriol were equally effective in the prevention of glucocorticoid-induced osteoporosis in patients with a renal or cardiac transplant. ${ }^{24,25}$ We compared the effects of alfacalcidol and alendronate in patients with a rheumatic disease who were receiving glucocorticoids.

METHODS

\section{STUDY DESIGN}

During our 18-month, double-blind, double-placebo-controlled study, we enrolled 201 patients of all racial and ethnic groups between the ages of 18 and 90 years who had a rheumatic disease and either were starting glucocorticoid therapy or had begun glucocorticoid therapy within the previous 12 weeks at a daily dose of at least $7.5 \mathrm{mg}$ of pred- nisone or its equivalent. The anticipated duration of glucocorticoid treatment was six months or more for all patients.

Exclusion criteria were glucocorticoid treatment for longer than the previous 12 weeks; therapy with hormone-replacement agents, anabolic steroids, calcitonin, active vitamin $\mathrm{D}_{3}$ analogues, fluoride, or bisphosphonates during the previous 12 months; or the presence of primary hyperparathyroidism, hyperthyroidism, or hypothyroidism in the year before the study began. Patients who were pregnant or breast-feeding were excluded, as were patients with metabolic bone diseases, documented hypocalcemia or hypercalciuria, a creatinine clearance of less than $50 \mathrm{ml}$ per minute, or a history of nephrolithiasis during the previous five years.

After patients had provided written informed consent, they were randomly assigned to receive oral treatment with either alendronate $(10 \mathrm{mg})$ and a look-alike placebo capsule of alfacalcidol or alfacalcidol (1 $\mu \mathrm{g})$ and a placebo tablet of alendronate, all once daily. Because of ethical considerations, an untreated control group was not included in this study. A person in the pharmacy of the coordinating center who was not otherwise involved in the study performed the stratified randomization with a concealed, computer-generated randomization procedure. Patients were stratified according to the initial daily dose of glucocorticoids they received ( $\leq 15 \mathrm{mg}$ or $>15 \mathrm{mg}$ ), sex, age ( $\leq 50$ years or $>50$ years), and the presence or absence of morphometric vertebral deformities at baseline.

The outpatient clinics of 23 departments of rheumatology in the Netherlands referred $210 \mathrm{pa}-$ tients for screening during an 18-month enrollment period. The medical ethics committees of all participating centers approved the study protocol. Of the 210 eligible patients (Fig. 1), 9 declined to participate. The first patient started treatment with a study medication in May 2000, and the last patient finished the study in October 2003. Patients were seen three weeks before the start of the study, the day study medication was started (baseline), and subsequently every third month. At baseline, the intake of dietary calcium was estimated with a questionnaire, the type of rheumatic disease was noted, and inclusion and exclusion criteria were checked. Patients with a dietary intake of less than $1000 \mathrm{mg}$ of calcium per day received a tablet that 
contained $500 \mathrm{mg}$ of elemental calcium per day. Patients with a deficiency of 25-hydroxyvitamin D (defined by a serum level of $<30 \mathrm{nmol}$ per liter) received $400 \mathrm{IU}$ of cholecalciferol per day. At each visit, any change in the glucocorticoid dose was recorded. Patients were asked about back pain, and the occurrence of any nonvertebral fracture was recorded.

The primary efficacy end point was the percent change in bone mineral density of the lumbar spine (lumbar vertebrae 2 through 4 ) at 18 months. Secondary efficacy end points were the percent change in bone mineral density of the femoral neck and total hip at 18 months and the incidence of morphometric vertebral deformities, symptomatic vertebral fractures, and nonvertebral fractures.

\section{MEASUREMENT OF BONE MINERAL DENSITY}

Bone mineral density of the lumbar spine, femoral neck, and total hip was measured at baseline and at 6,12 , and 18 months with dual-energy x-ray absorptiometry (DEXA); 11 centers used Hologic machines (Hologic), and 12 centers used Lunar machines (General Electric). Bone mineral density was expressed as grams per square centimeter, and $\mathrm{T}$ scores and $\mathrm{z}$ scores were calculated separately for Hologic and Lunar machines.

\section{RADIOGRAPHIC ANALYSIS}

Radiography of the lateral lumbar and thoracic spine was performed at baseline and at 18 months and at any time during the study in patients with new back pain. All radiographs were centrally assessed in a blinded fashion by two trained observers, the corresponding author and one independent reader, according to the method of Kleerekoper et al. ${ }^{26}$ This method consists of visual inspection of the spine from thoracic vertebra 4 through lumbar vertebra 5 , comparing each vertebra with those below and above. If an abnormally shaped vertebra is identified, the anterior, middle, and posterior heights of this vertebra are measured with a ruler and scored as follows: 1 (only end-plate deformity, with a middle height of less than 85 percent), 2 (an anterior-wedge deformity, with an anterior height of less than 85 percent), or 3 (a compression deformity, with all three heights of less than 85 percent); a score of 0 denotes normal shape and dimensions. A new vertebral deformity on a radiograph that was obtained because of new back pain was defined as a symptomatic vertebral fracture.

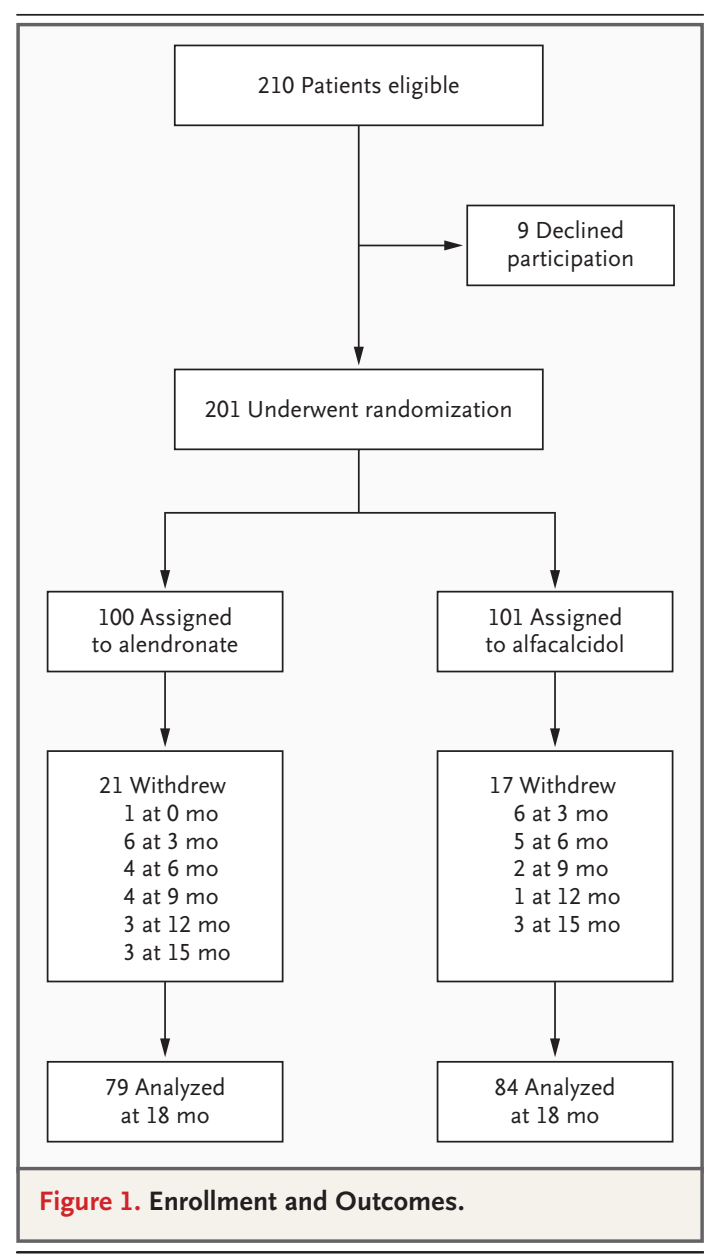

Nonvertebral fractures were confirmed by radiography.

\section{BIOCHEMICAL MEASUREMENT}

Serum for measurement of calcium, creatinine, and albumin was collected at baseline and at 1, 2, $3,6,9,12,15$, and 18 months and was analyzed at the laboratory of each participating center. Standardization of the data was done through a conversion method, according to the chemistry laboratory protocol of Covance Virtual Central Laboratory in Zeist, the Netherlands, where data were centrally pooled. Calcium was corrected for serum albumin according to the following formula: cal cium $+[(40-$ albumin $) \times 0.02] .{ }^{27}$ Because of logistic problems in this multicenter trial, 24-hour measurement of urinary calcium was not performed. At baseline, serum 25-hydroxyvitamin D was measured and analyzed by radioimmunoassay at a central laboratory. Measurement of serum intact para- 
thyroid hormone was performed at baseline and at $1,2,3$, and 18 months by chemiluminescence immunoassay; serum carboxy-terminal propeptide of type 1 procollagen (P1CP) was measured at baseline and at 6,12 , and 18 months by radioimmunoassay; and fasting (second void) urinary $\mathrm{N}$-telopeptide was measured at baseline and 3, 6, $9,12,15$, and 18 months by enzyme-linked immunosorbent assay. Bone-marker samples were collected in the morning and stored at $-70^{\circ} \mathrm{C}$ at a central laboratory for batch analyses.

\section{SAFETY CRITERIA AND ADVERSE EVENTS}

At each visit, all adverse events were recorded and the relation of the event with the study drugs scored as "no relation," "possible," "probable," or "definite." The severity of the event was scored as mild, moderate, or severe. Hypercalcemia was defined as a serum calcium level corrected for albumin of more than $2.7 \mathrm{mmol}$ per liter and hypocalcemia as a corrected level of less than $2.2 \mathrm{mmol}$ per liter. If hypercalcemia occurred in patients who were receiving supplemental calcium or cholecalciferol, the supplementation was discontinued. If hypercalcemia persisted at a second check two weeks later, the dose of either alfacalcidol or placebo was reduced to once every two days until the end of the study. This dose reduction was the first step in patients who were not receiving supplemental calcium or cholecalciferol in case of hypercalcemia. If hypercalcemia still persisted after two weeks of a reduced dose of trial medication, the trial medication was stopped and the patient continued to be followed.

\section{STATISTICAL ANALYSIS}

Given a two-sided alpha level of 0.05 , the study had a statistical power of 80 percent to detect a mean $( \pm S D)$ difference between the two groups in bone mineral density of $5 \pm 6$ percent after 18 months, assuming that 200 patients were enrolled and that 40 percent of patients were lost to follow-up. Repeated-measures analysis of differences between the two groups in changes from baseline in bone mineral density were performed with the use of model-based restricted maximum-likelihood estimates of the means according to group, to include all available data. Differences between the treatment groups in continuous biochemical variables were tested for significance at 18 months with a two-sample t-test or Mann-Whitney U test as appropriate.
Efficacy and safety analyses included all patients for whom data on bone mineral density were available, regardless of whether they were still receiving study medication. Ordinal data were tested with the use of the chi-square test. Proportionalhazards regression analysis was used to adjust for the difference in the number of vertebral deformities in the two treatment groups at baseline. Hazard ratios were calculated for differences in the incidence of vertebral and nonvertebral fractures and of hypercalcemia between the two treatment groups. All tests were two-sided, and all analyses were performed at the coordinating hospital, the University Medical Center Utrecht, in Utrecht, the Netherlands.

\section{RESULTS}

Baseline characteristics and bone mineral density of the two groups are shown in Table 1 . The mean daily glucocorticoid doses during the study were $11.8 \pm 8.8 \mathrm{mg}$ in the alendronate group and $11.1 \pm 7.3 \mathrm{mg}$ in the alfacalcidol group, a difference of $0.7 \mathrm{mg}$ per day ( 95 percent confidence interval, -1.6 to 3.0), and the mean cumulative glucocorticoid doses were $5790 \pm 3663 \mathrm{mg}$ and $5704 \pm 3375 \mathrm{mg}$, respectively, a difference of $86 \mathrm{mg}$ (95 percent confidence interval, -899 to 1070 ).

\section{WITHDRAWAL FROM THE STUDY}

In the alendronate group, one patient died of a perforated sigmoid colon due to diverticulitis and another died from newly discovered non-Hodgkin's lymphoma. In the alfacalcidol group, one patient died from a stroke. Before the 18-month visit, 19 patients in the alendronate group withdrew (1 before starting alendronate) and 2 died, and 16 withdrew in the alfacalcidol group and 1 died, accounting for rates of retention of 79 and 83 percent, respectively. Reasons for discontinuation in the two groups were lack of motivation in eight patients in the alendronate group and seven in the alfacalcidol group; gastrointestinal side effects in five and two, respectively; cancer in two and one, respectively; and other conditions in three and six, respectively. None of these differences was significant. At 18 months, bone mineral density of the lumbar spine was measured in 79 patients in the alendronate group and 84 in the alfacalcidol group; bone mineral density of the femoral neck was measured in 73 and 70 patients, respectively; and bone mineral density of the total hip was mea- 


\begin{tabular}{|c|c|c|c|c|}
\hline Variable & \multicolumn{2}{|c|}{$\begin{array}{l}\text { Alendronate } \\
\qquad(\mathrm{N}=99)\end{array}$} & \multicolumn{2}{|c|}{$\begin{array}{l}\text { Alfacalcidol } \\
(\mathrm{N}=101)\end{array}$} \\
\hline Age $-y r$ & \multicolumn{2}{|c|}{$60 \pm 14$} & \multicolumn{2}{|c|}{$62 \pm 15$} \\
\hline \multicolumn{5}{|l|}{ Female sex - no. } \\
\hline Premenopausal & \multicolumn{2}{|c|}{7} & \multicolumn{2}{|c|}{10} \\
\hline Postmenopausal & \multicolumn{2}{|c|}{52} & \multicolumn{2}{|c|}{55} \\
\hline \multicolumn{5}{|l|}{ Race or ethnic group - no. $\dagger^{\dagger}$} \\
\hline White & \multicolumn{2}{|c|}{93} & \multicolumn{2}{|c|}{87} \\
\hline Black & \multicolumn{2}{|c|}{2} & \multicolumn{2}{|c|}{6} \\
\hline Other & \multicolumn{2}{|c|}{4} & \multicolumn{2}{|c|}{8} \\
\hline $\begin{array}{c}\text { Dose of glucocorticoid (prednisone } \\
\text { equivalent) }-\mathrm{mg} / \text { day }\end{array}$ & \multicolumn{2}{|c|}{$23 \pm 20$} & \multicolumn{2}{|c|}{$22 \pm 18$} \\
\hline $\begin{aligned} \text { Serum } & \text { 25-hydroxyvitamin D level } \\
& <30 \mathrm{nmol} / \mathrm{ml}-\text { no. }\end{aligned}$ & \multicolumn{2}{|c|}{19} & \multicolumn{2}{|c|}{21} \\
\hline Dietary calcium intake $-\mathrm{mg} /$ day & \multicolumn{2}{|c|}{$947 \pm 357$} & \multicolumn{2}{|c|}{$996 \pm 330$} \\
\hline Calcium supplementation — no. & \multicolumn{2}{|c|}{58} & \multicolumn{2}{|c|}{56} \\
\hline Height $-\mathrm{cm}$ & \multicolumn{2}{|c|}{$169 \pm 10$} & \multicolumn{2}{|c|}{$169 \pm 9$} \\
\hline Weight — kg & \multicolumn{2}{|c|}{$74 \pm 13$} & \multicolumn{2}{|c|}{$73 \pm 12$} \\
\hline Vertebral deformity — no. & \multicolumn{2}{|c|}{6} & \multicolumn{2}{|c|}{14} \\
\hline Diagnosis - no. & & & & \\
\hline Polymyalgia rheumatica & & & 3 & \\
\hline Rheumatoid arthritis & & & 4 & \\
\hline Other & & & 2 & \\
\hline & $\begin{array}{l}\text { Hologic System } \\
\qquad(N=55)\end{array}$ & $\begin{array}{l}\text { Lunar System } \\
\qquad(\mathrm{N}=44)\end{array}$ & $\begin{array}{l}\text { Hologic System } \\
\qquad(N=58)\end{array}$ & $\begin{array}{l}\text { Lunar System } \\
\qquad(\mathrm{N}=43)\end{array}$ \\
\hline $\begin{array}{l}\text { Site of bone mineral density } \\
\text { measurement }\end{array}$ & & & & \\
\hline Lumbar spine (L2-L4) & & & & \\
\hline Mean $-\mathrm{g} / \mathrm{cm}^{2}$ & $0.99 \pm 0.17$ & $1.15 \pm 0.23$ & $1.02 \pm 0.16$ & $1.19 \pm 0.23$ \\
\hline T score & $-0.91 \pm 1.55$ & $-0.38 \pm 1.85$ & $-0.71 \pm 1.45$ & $-0.06 \pm 1.92$ \\
\hline z score & $0.05 \pm 1.54$ & $0.39 \pm 1.59$ & $0.42 \pm 1.51$ & $0.75 \pm 1.69$ \\
\hline Femoral neck & & & & \\
\hline Mean $-\mathrm{g} / \mathrm{cm}^{2}$ & $0.78 \pm 0.14$ & $0.89 \pm 0.16$ & $0.79 \pm 0.15$ & $0.88 \pm 0.15$ \\
\hline T score & $-1.40 \pm 1.15$ & $-0.79 \pm 1.41$ & $-1.23 \pm 1.28$ & $-0.98 \pm 1.30$ \\
\hline z score & $-0.07 \pm 0.96$ & $0.12 \pm 0.97$ & $0.11 \pm 1.13$ & $0.09 \pm 1.10$ \\
\hline Total hip & & & & \\
\hline Mean $-\mathrm{g} / \mathrm{cm}^{2}$ & $0.91 \pm 0.16$ & $0.95 \pm 0.16$ & $0.89 \pm 0.13$ & $0.90 \pm 0.13$ \\
\hline T score & $-0.79 \pm 1.18$ & $-0.70 \pm 1.22$ & $-0.89 \pm 1.09$ & $-1.05 \pm 1.03$ \\
\hline z score & $0.09 \pm 1.06$ & $0.13 \pm 0.88$ & $0.02 \pm 1.09$ & $-0.03 \pm 1.00$ \\
\hline
\end{tabular}

* Plus-minus values are means \pm SD. There were no significant differences between the two groups. The T score expresses the patient's bone mineral density as the number of SDs above or below the mean bone mineral density of young adults of the same sex and race, and the z score, the number of SDs above or below the mean bone mineral density of control persons of the same age, sex, and race.

$\dagger$ Race or ethnic group was designated by the investigators. 


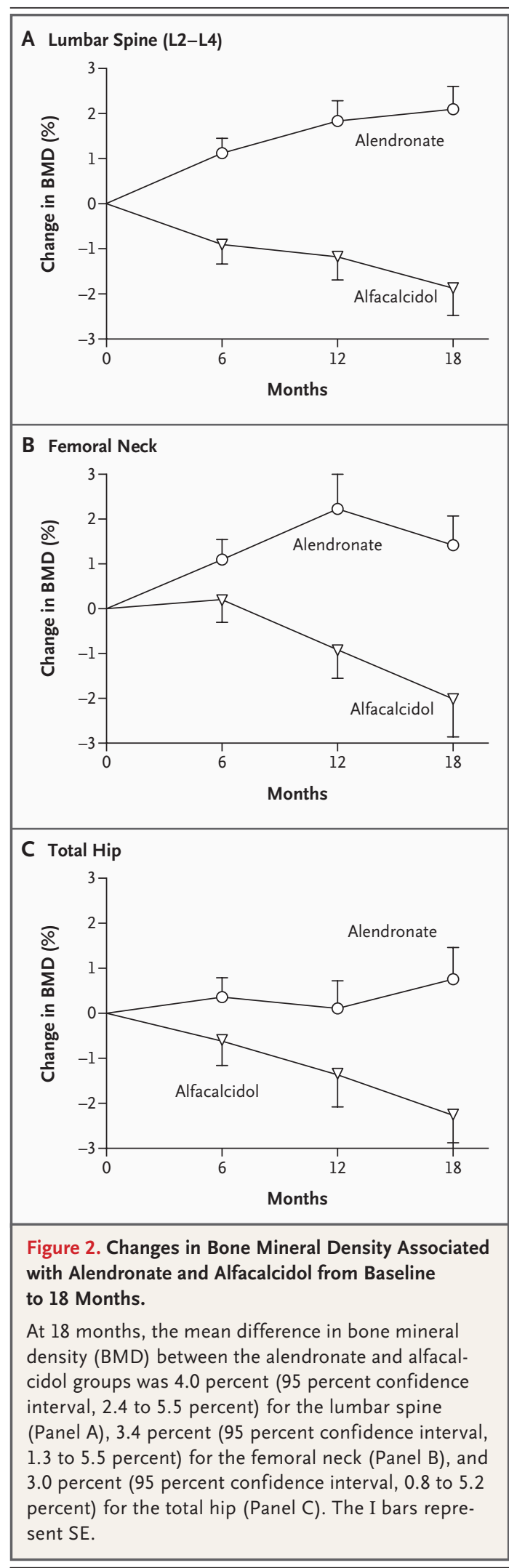

sured in 61 and 52 patients, respectively. At 18 months, three of the patients who had withdrawn from the alendronate group, but none who had withdrawn from the alfacalcidol group, underwent measurement of bone mineral density and laboratory tests.

\section{CHANGES IN BONE MINERAL DENSITY}

After 18 months, the mean bone mineral density of the lumbar spine had increased by 2.1 percent in the alendronate group (95 percent confidence interval, 1.1 to 3.1 percent) and decreased by 1.9 percent in the alfacalcidol group (95 percent confidence interval, -3.1 to -0.7 percent), an absolute difference between the two groups of 4.0 percent (95 percent confidence interval, 2.4 to 5.5 percent) (Fig. 2A). The bone mineral density of the femoral neck had increased by 1.4 percent in the alendronate group (95 percent confidence interval, 0.1 to 2.7 percent) and decreased by 2.0 percent in the alfacalcidol group (95 percent confidence interval, -3.7 to -0.3 percent), an absolute difference of 3.4 percent ( 95 percent confidence interval, 1.3 to 5.5 percent) (Fig. 2B). The bone mineral density of the total hip had increased by 0.8 percent in the alendronate group ( 95 percent confidence interval, -0.7 to 2.2 percent) and decreased by 2.2 percent in the alfacalcidol group ( 95 percent confidence interval, -4.0 to -0.5 percent), an absolute difference of 3.0 percent ( 95 percent confidence interval, 0.8 to 5.2 percent) (Fig. 2 C). The treatment effect was significant for the primary efficacy end point $(\mathrm{P}<0.001$ by repeated-measures analysis).

\section{INCIDENCE OF VERTEBRAL DEFORMITIES AND NONVERTEBRAL FRACTURES}

In the alendronate group, three patients had a new vertebral deformity. In the alfacalcidol group, eight patients had 13 new vertebral deformities (of which 5 were symptomatic in three patients); the hazard ratio for vertebral deformities in the alendronate group as compared with the alfacalcidol group was 0.4 (95 percent confidence interval, 0.1 to 1.4). Adjustment for the number of vertebral fractures at baseline also yielded a hazard ratio of 0.4 (95 percent confidence interval, 0.1 to 1.4$)$. In either group, only one of the patients with a new vertebral deformity had a deformity at baseline.

In the alendronate group, two patients had fractures: one of the midfoot and another of the forearm. In the alfacalcidol group, three patients had fractures: one of the femoral neck, one of the 
Figure 3. Changes in Levels of Serum Calcium Corrected for Albumin, Serum Parathyroid Hormone, Serum P1CP, and Urinary $\mathrm{N}$-Telopeptide.

At 18 months, the mean differences between the alendronate and alfacalcidol groups in the serum calcium level were $-0.24 \mathrm{mg}$ per deciliter $(-0.06 \mathrm{mmol}$ per liter $)$ (95 percent confidence interval, -0.44 to -0.08 [-0.1] to -0.02$]$ ) (Panel A); in the serum parathyroid hormone level, $2.4 \mathrm{pmol}$ per liter ( 95 percent confidence interval, 1.7 to 3.1 ) (Panel B); in the serum PICP level, -400 pmol per liter (95 percent confidence interval, -568 to -111 ) (Panel C); and in the urinary $N$-telopeptide level, -22 nmol per liter ( 95 percent confidence interval, -146 to 101) (Panel D). The I bars represent SE. To convert values for calcium to milligrams per deciliter, divide by 0.250 .

pubic bone, and one of a rib; the hazard ratio for nonvertebral fracture in the alendronate group as compared with the alfacalcidol group was 0.7 (95 percent confidence interval, 0.1 to 4.0 ).

\section{LABORATORY MEASUREMENTS}

At 18 months, the difference between the alendronate group and the alfacalcidol group in the change from baseline in serum calcium level was $-0.24 \mathrm{mg}$ per deciliter $(-0.06 \mathrm{mmol}$ per liter) ( 95 percent confidence interval, -0.44 to -0.08 [ -0.11 to -0.02$]$ ) (Fig. 3A). The difference between groups in the change from baseline in the serum creatinine level was $-0.03 \mathrm{mg}$ per deciliter $(-2.6 \mu \mathrm{mol}$ per liter) (95 percent confidence interval, 0.08 to $0.03[-7.5$ to 2.3]). The difference between groups in the change from baseline in the serum parathyroid hormone level was 2.4 pmol per liter (95 percent confidence interval, 1.7 to 3.1) (Fig. 3B). The difference between groups in the change from baseline in the serum P1CP level was -400 pmol per liter ( 95 percent confidence interval, -568 to -111 ) (Fig. 3C). The difference between groups in the change from baseline in the urinary $\mathrm{N}$-telopeptide level was $-22 \mathrm{nmol}$ per liter (95 percent confidence interval, -146 to 101) (Fig. 3D).

\section{ADVERSE EVENTS}

Table 2 lists the adverse events during the study. One patient in the alendronate group had an esophageal ulcer. Three patients in the alendronate group had hypercalcemia, as compared with seven in the alfacalcidol group (hazard ratio, 0.45; 95 percent confidence interval, 0.12 to 1.71 ). In one patient in the alendronate group, calcium supplementation was stopped because of hypercalcemia, but no re-

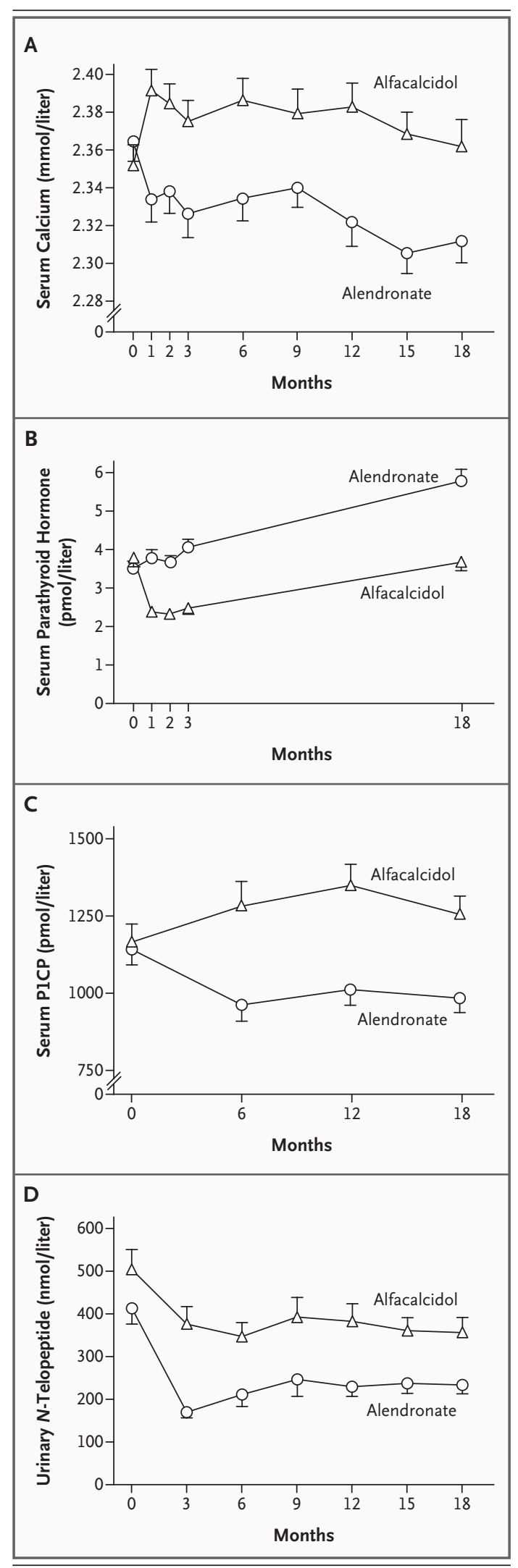




\begin{tabular}{|c|c|c|c|}
\hline \multirow[t]{2}{*}{ Adverse Event } & $\begin{array}{l}\text { Alendronate } \\
\qquad(\mathrm{N}=98)\end{array}$ & $\begin{array}{c}\text { Alfacalcidol } \\
(\mathrm{N}=100)\end{array}$ & Hazard Ratio $(95 \% \mathrm{Cl})$ \\
\hline & \multicolumn{2}{|c|}{ no. of patients } & \\
\hline$\geq 1$ Adverse events & 68 & 67 & $1.02(0.79-1.33)$ \\
\hline Related to study drug $\dagger$ & 21 & 14 & $1.44(0.77-2.69)$ \\
\hline \multicolumn{4}{|l|}{ Withdrawals because of adverse event } \\
\hline Related to study drug $\dagger$ & 3 & 1 & $3.00(0.32-28.40)$ \\
\hline Related to other adverse event & 3 & 6 & $0.53(0.14-2.04)$ \\
\hline Death & 2 & 1 & $2.02(0.12-21.90)$ \\
\hline Gastrointestinal adverse event & 35 & 52 & $0.77(0.54-1.10)$ \\
\hline Dyspepsia & 7 & 8 & $0.90(0.34-2.39)$ \\
\hline Diarrhea & 3 & 7 & $0.45(0.12-1.71)$ \\
\hline Nausea & 2 & 8 & $0.27(0.06-1.24)$ \\
\hline Abdominal pain & 5 & 4 & $1.26(0.35-4.57)$ \\
\hline Other symptoms & 18 & 25 & $0.78(0.45-1.35)$ \\
\hline Other adverse events & 18 & 17 & $1.07(0.58-1.97)$ \\
\hline Skin disorder & 11 & 9 & $1.22(0.53-2.83)$ \\
\hline Headache & 7 & 8 & $0.90(0.34-2.39)$ \\
\hline Laboratory adverse events & 47 & 44 & $1.06(0.75-1.49)$ \\
\hline Hypocalcemia (calcium <8.8 mg/dl [2.2 mmol/liter]) & 36 & 21 & $1.55(0.96-2.50)$ \\
\hline Increase in creatinine $>0.2 \mathrm{mg} / \mathrm{dl}(22 \mu \mathrm{mol} /$ liter $) \mathbb{}$ & 8 & 16 & $0.55(0.24-1.23)$ \\
\hline Hypercalcemia (calcium >10.8 mg/dl [2.7 mmol/liter]) & 3 & 7 & $0.45(0.12-1.71)$ \\
\hline
\end{tabular}

* Patients could have had one or more adverse events, which were reported by the patients themselves or by investigators. No data were available about adverse events for two patients (one in each group).

$\dagger$ The adverse event was either probably or definitely attributable to the use of a study medication.

$t$ The cause of death was not related to the use of a study medication. In the alendronate group, one patient died from a perforated sigmoid colon due to diverticulitis, and one patient died from non-Hodgkin's lymphoma. In the alfacalcidol group, one patient died from a cerebrovascular accident.

$\int$ The serum creatinine level was compared with the previous measurement.

duction in the dose of alfacalcidol or placebo was necessary, because the serum calcium level normalized. There was no report of thyroid or renal dysfunction during the study. In the alfacalcidol group, one patient withdrew from the study because of congestive heart failure and another died of a cerebrovascular accident.

\section{DISCUSSION}

In patients with a rheumatic disease in whom glucocorticoid therapy was initiated at a daily dose of at least $7.5 \mathrm{mg}$ of prednisone or the equivalent and who were treated for 18 months with alendronate or alfacalcidol, we found a significant difference of 4.0 percent in bone mineral density of the lum- bar spine favoring alendronate. Similar results were observed for bone mineral density of the femoral neck and total hip. These differences result from an increase in bone mineral density in patients receiving alendronate and a decrease in those receiving alfacalcidol.

One third of the patients in our study had rheumatoid arthritis, one third had polymyalgia rheumatica, and one third had another rheumatic disease. A previous study indicated that patients with rheumatoid arthritis who received glucocorticoids had twice the number of vertebral deformities as did such patients not receiving glucocorticoids. ${ }^{1}$ In patients with polymyalgia rheumatica receiving low-dose glucocorticoids, accelerated bone loss has been demonstrated in the lumbar spine. ${ }^{28}$ 
Alfacalcidol has dual effects on bone. It increases bone formation by the stimulation of osteoblasts and has an antiresorptive effect. ${ }^{13}$ Alfacalcidol suppresses the synthesis and release of parathyroid hormone and increases the intestinal absorption and reabsorption of calcium in the distal renal tubules. ${ }^{29}$ In rats, active vitamin $\mathrm{D}_{3}$ metabolites have been shown to improve the microarchitecture and strength of bone. ${ }^{13,30}$ All these properties could be beneficial in the prevention of glucocorticoid-induced osteoporosis. Indeed, active vitamin $\mathrm{D}_{3}$ metabolites were more effective in preserving bone mineral density and decreasing the risk of vertebral deformities during glucocorticoid therapy than was no treatment, placebo, or treatment with vitamin $\mathrm{D}_{3}$, calcium, or both. ${ }^{16}$ Bisphosphonates such as alendronate are effective in the treatment and prevention of glucocorticoidinduced osteoporosis. ${ }^{18-20}$ Only one study (with an open-label design) in patients with a rheumatic disease who were receiving glucocorticoids has directly compared the effect of alendronate with that of calcitriol; in that study, alendronate was superior in the prevention of glucocorticoid-induced osteoporosis. ${ }^{21}$

In our study, levels of bone markers suggest stimulation of bone formation in the alfacalcidol group, but the increase in serum P1CP levels was probably caused, in part, by the gradual decrease in the glucocorticoid dose during the study, which probably caused progressively less inhibition of osteoblast function by glucocorticoids. Despite this trend of stimulation of bone formation, the bone mineral density in the alfacalcidol group decreased. Although more new vertebral deformities occurred in this group than in the group receiving alendronate, the difference was not significant. In the alendronate group, levels of urinary $\mathrm{N}$-telopeptide decreased, indicating a reduction in bone resorption, coupled with a small decrease in the serum P1CP level. The serum parathyroid hormone level increased in this group, probably owing to a decrease in the serum calcium level due to the inhibition of bone resorption. Another ex- planation could be that there were more patients with a deficiency of 25-hydroxyvitamin D than were defined by our cutoff serum level of $30 \mathrm{nmol}$ per liter. We believe that with the use of alendronate, adequate supplementation with calcium and vitamin $\mathrm{D}_{3}$ is required.

Bone mineral density in the alendronate group increased, as compared with that in the alfacalcidol group, and fewer patients in the alendronate group had new vertebral deformities, although the difference was not significant. Thus, alendronate may inhibit bone loss in glucocorticoid-induced osteoporosis more effectively than does alfacalcidol. The benefits of bisphosphonates in glucocorticoid-induced osteoporosis have been ascribed primarily to their antiresorptive effect and secondarily to possible inhibition of apoptosis of osteoblasts. ${ }^{31,32}$

There were few side effects of either treatment. Transient hypercalcemia developed in only seven patients receiving alfacalcidol. Because of logistic difficulties, we did not perform 24-hour urinary calcium measurement, but hypercalciuria is often found in patients receiving active vitamin $\mathrm{D}_{3}$ metabolites. ${ }^{25}$ Therefore, in addition to the measurement of serum calcium levels, urinary calcium monitoring may be necessary for safety reasons in patients receiving active vitamin $\mathrm{D}_{3}$.

In summary, our study indicates that alendronate is more effective than alfacalcidol in the prevention of glucocorticoid-induced bone loss.

Supported by a grant (OG67, to Dr. de Nijs) from the Dutch Health Care Insurance Board. Merck provided matched alendronate and placebo tablets. Teva Pharmaceuticals provided matched alfacalcidol and placebo capsules.

Dr. de Nijs reports having received grant support from the Dutch Health Care Insurance Board; Dr. Lems, consulting and lecture fees from Eli Lilly, Merck, and Procter \& Gamble; Dr. Buskens, consulting fees from Chiron Vaccines, Baxter, Organon, and Janssen-Cilag; Dr. Geusens, lecture fees from Eli Lilly, Merck, Procter \& Gamble, and Wyeth; and Dr. Dijkmans, consulting fees from Abbott, Merck, Novartis, Roche, and SanofiAventis and lecture fees from Schering-Plough. No other potential conflict of interest relevant to this article was reported.

We are indebted to E.M. Monninkhof for help with the statistical analyses.

APPENDIX

The following investigators, all in the Netherlands, also participated in the STOP study: Medical Center Alkmaar, Alkmaar — W. Swen; Outdoor Patient Center Buitenveldert, Amsterdam — G. Schardijn; Gelre Hospital, Apeldoorn — F. Eggelmeijer; Leyenburg Hospital, Den Haag — H. Ronday; Scheper Ziekenhuis, Emmen — H. Lim; Oosterschelde Hospital, Goes — P. de Sonnaville; Atrium Medical Center, Heerlen — H. Houben; Sint Antonius Hospital, Nieuwegein - E.J. ter Borg; Laurentius Hospital, Roermond - P. Jacobs; Sint Franciscus Hospital, Rotterdam — H. van Paassen; Medical Center Rijnmond Zuid, Rotterdam — H. Markusse (deceased), A. Romme; Hospital Rivierenland, Tiel — K.J. Korff; Mesos Medical Center, Utrecht — J. Ehrlich; Zuwe Hofpoort Hospital, Woerden - M. van Lieshout, J. Macfarlane; Isala Hospital, Zwolle — S. Zanen. 
REFERENCES

1. de Nijs RN, Jacobs JW, Bijlsma JW, et al. Prevalence of vertebral deformities and symptomatic vertebral fractures in corticosteroid treated patients with rheumatoid arthritis. Rheumatology (Oxford) 2001 40:1375-83.

2. van Staa TP, Leufkens HG, Cooper C The epidemiology of corticosteroid-induced osteoporosis: a meta-analysis. Osteoporos Int 2002;13:777-87.

3. Vestergaard P, Olsen ML, Paaske Johnsen S, Rejnmark L, Sorensen HT Mosekilde L. Corticosteroid use and risk of hip fracture: a population-based casecontrol study in Denmark. J Intern Med 2003;254:486-93.

4. Manolagas SC, Weinstein RS. New developments in the pathogenesis and treatment of steroid-induced osteoporosis. J Bone Miner Res 1999;14:1061-6.

5. Canalis E, Delany AM. Mechanisms of glucocorticoid action in bone. Ann $\mathrm{N}$ Acad Sci 2002;966:73-81.

6. Klein RG, Arnaud SB, Gallagher JC, DeLuca HF, Riggs BL. Intestinal calcium absorption in exogenous hypercortisonism role of 25-hydroxyvitamin D and corticosteroid dose. J Clin Invest 1977;60:253-9.

7. Suzuki Y, Ichikawa Y, Saito E, Homm M. Importance of increased urinary calcium excretion in the development of secondary hyperparathyroidism of patients under glucocorticoid therapy. Metabolism 1983;32:151-6.

8. Rubin MR, Bilezikian JP. The role of parathyroid hormone in the pathogenesis of glucocorticoid-induced osteoporosis a re-examination of the evidence. J Clin Endocrinol Metab 2002;87:4033-41.

9. Verstraeten A, Dequeker J. Vertebra and peripheral bone mineral content and fracture incidence in postmenopausal patients with rheumatoid arthritis: effect of low dose corticosteroids. Ann Rheum Dis 1986;45:852-7.

10. Michel BA, Bloch DA, Wolfe F, Fries JF Fractures in rheumatoid arthritis: an evaluation of associated risk factors. J Rheumatol 1993;20:1666-9.

11. Van Staa TP, Leufkens HG, Abenhaim L, Zhang B, Cooper C. Use of oral corticosteroids and risk of fractures. J Bone Miner Res 2000;15:993-1000

12. Sato F, Ouchi Y, Okamoto Y, et al. Ef- fects of vitamin D2 analogs on calcium metabolism in vitamin $\mathrm{D}$-deficient rats and in MC3T3-E1 osteoblastic cells. Res Exp Med (Berl) 1991;191:235-42.

13. Shiraishi A, Takeda S, Masaki T, et al. Alfacalcidol inhibits bone resorption and stimulates formation in an ovariecto mized rat model of osteoporosis: distinct actions from estrogen. J Bone Miner Res 2000;15:770-9.

14. Reginster JY, Kuntz D, Verdickt W, et al. Prophylactic use of alfacalcidol in corticosteroid-induced osteoporosis. Osteoporos Int 1999;9:75-81

15. Ringe JD, Coster A, Meng T, Schach E, Umbach R. Treatment of glucocorticoid-induced osteoporosis with alfacal cidol/calcium versus vitamin $\mathrm{D} /$ calcium. Calcif Tissue Int 1999;65:337-40.

16. de Nijs RN, Jacobs JW, Algra A, Lem WF, Bijlsma JW. Prevention and treatment of glucocorticoid-induced osteoporosis with active vitamin $\mathrm{D}(3)$ analogues: a re view with meta-analysis of randomized controlled trials including organ transplantation studies. Osteoporos Int 2004, 15:589-602.

17. Rogers MJ. New insights into the moecular mechanisms of action of bisphosphonates. Curr Pharm Des 2003;9:2643-58. 18. Gonnelli S, Rottoli P, Cepollaro C, et al. Prevention of corticosteroid-induced osteoporosis with alendronate in sarcoid patients. Calcif Tissue Int 1997;61:382-5.

19. Saag KG, Emkey R, Schnitzer TJ, et al. Alendronate for the prevention and treatment of glucocorticoid-induced osteoporosis. N Engl J Med 1998;339:292-9. 20. Adachi JD, Saag KG, Delmas PD, et al Two-year effects of alendronate on bone mineral density and vertebral fracture in patients receiving glucocorticoids: a randomized, double-blind, placebo-controlled extension trial. Arthritis Rheum 2001;44:202-11.

21. Sambrook PN, Kotowicz M, Nash P, et al. Prevention and treatment of glucocorticoid-induced osteoporosis: a comparison of calcitriol, vitamin D plus calcium, and alendronate plus calcium. J Bone Miner Res 2003;18:919-24.

22. Kovac D, Lindic J, Kandus A, Bren AF. Prevention of bone loss in kidney graft recipients. Transplant Proc 2001;33:1144-5.
23. Giannini S, D’Angelo A, Carraro G, et al. Alendronate prevents further bone loss in renal transplant recipients. J Bone Miner Res 2001;16:2111-7.

24. Jeffery JR, Leslie WD, Karpinski ME, Nickerson PW, Rush DN. Prevalence and treatment of decreased bone density in renal transplant recipients: a randomized prospective trial of calcitriol versus alendronate. Transplantation 2003;76:1498-502. 25. Shane E, Addesso V, Namerow PB, et al. Alendronate versus calcitriol for the prevention of bone loss after cardiac transplantation. N Engl J Med 2004;350: 767-76.

26. Kleerekoper M, Parfitt AM, Ellis BI. Measurements of vertebral fracture rates in osteoporosis. In: Christiansen C, Arnaud CD, Nordin BEC, Parfitt AM, Peck WA, Riggs BL, eds. Proceedings of the Copenhagen International Symposium on Osteoporosis June 3-8. Copenhagen: Aalberg Stiftsbogtrykkeri, 1984:103-9.

27. Payne RB, Little AJ, Williams RB, Milner JR. Interpretation of serum calcium in patients with abnormal serum proteins. Br Med J 1973;4:643-6.

28. Pearce G, Ryan PF, Delmas PD, Tabensky DA, Seeman E. The deleterious effects of low-dose corticosteroids on bone density in patients with polymyalgia rheumatica. Br J Rheumatol 1998;37:292-9.

29. Schacht E. Rationale for treatment of involutional osteoporosis in women and for prevention and treatment of corticosteroid-induced osteoporosis with alfacalcidol. Calcif Tissue Int 1999;65:317-27. 30. Aerssens J, van Audekercke R, Talalaj $\mathrm{M}$, et al. Effect of 1 alpha-vitamin D3 on bone strength and composition in growing rats with and without corticosteroid treatment. Calcif Tissue Int 1994;55:44350.

31. Plotkin LI, Weinstein RS, Parfitt AM, Roberson PK, Manolagas SC, Bellido T. Prevention of osteocyte and osteoblast apoptosis by bisphosphonates and calcitonin. J Clin Invest 1999;104:1363-74.

32. Weinstein RS, Chen JR, Powers CC, et al. Promotion of osteoclast survival and antagonism of bisphosphonate-induced osteoclast apoptosis by glucocorticoids. J Clin Invest 2002;109:1041-8.

Copyright (c) 2006 Massachusetts Medical Society.

APPLY FOR JOBS ELECTRONICALLY AT THE NEJM CAREERCENTER Physicians registered at the NEJM CareerCenter can apply for jobs electronically using their own cover letters and CVs. You can keep track of your job-application history with a personal account that is created when you register with the CareerCenter and apply for jobs seen online at our Web site. Visit www.nejmjobs.org for more information. 